1 Authors: Claudio Hidalgo-Cantabrana ${ }^{\mathbf{1}}$, Patricia López ${ }^{\mathbf{1}, \mathbf{2}}$, Miguel Gueimonde ${ }^{\mathbf{1}}$, Clara G. de los

12 Reyes-Gavilán ${ }^{1}$, Ana Suárez ${ }^{2}$, Abelardo Margolles ${ }^{1}$ and Patricia Ruas-Madiedo ${ }^{1}{ }_{*}$

2

$4^{3} 3$

5 64 7

${ }^{8} 5$ 10

\title{
Title: Immune modulation capability of exopolysaccharides synthesised by lactic acid bacteria
} and bifidobacteria

\section{Addresses:}

${ }^{1}$ Department of Microbiology and Biochemistry of Dairy Products, Instituto de Productos Lácteos de Asturias - Consejo Superior de Investigaciones Científicas (IPLA-CSIC), Villaviciosa, Asturias, Spain

${ }^{2}$ Department of Functional Biology, Immunology Area, University of Oviedo, Oviedo, Asturias, Spain

* Corresponding author:

Instituto de Productos Lácteos de Asturias (IPLA-CSIC), Paseo Río Linares s/n, 33300 Villaviciosa, Asturias, Spain. Tel.: +34 985892131, Fax: +34 9852233, e-mail: ruas-madiedo@ipla.csic.es 


\section{Abstract}

During recent years the exopolysaccharides (EPS) produced by some strains of lactic acid bacteria and bifidobacteria have attracted the attention of researchers, mainly due to their potential technological applications. However, more recently it has been observed that some of these EPS present immunomodulatory properties, which suggest a potential effect on human health. Whereas EPS from lactic acid bacteria have been studied in some detail, those of bifidobacteria largely remain uncharacterized in spite of the ubiquity of EPS genes in Bifidobacterium genomes. In this review we have analysed the data collected in literature about the potential immune modulating capability of EPS produced by lactic acid bacteria and bifidobacteria. From this data analysis, as well as from results obtained in our group, a hypothesis relating the physico-chemical characteristics of EPS with their immune modulation capability was highlighted. We propose that EPS having negative charge and/or small size (molecular weight) are able to act as mild stimulators of immune cells, whereas those polymers non-charged and with a large size present a suppressive profile.

Keywords: exopolysaccharide, lactic acid bacteria, bifidobacteria, immune response, probiotic 


\section{Introduction}

\subsection{Bacterial EPS}

The ability to produce exo-cellular polysaccharides is widespread throughout the microbial world, from some algae, fungi and yeasts to prokaryotes. In the last case, polymers produced by Archaea isolated from diverse, extreme environments (extremophiles) have been receiving special attention in recent times due to their potential applications [45]. However, several biopolymers produced by Bacteria, both Gram-positive and Gram-negative, are currently well studied and characterized due to their industrial, medical and biotechnological uses [38, 47, 68]. Besides, it is known that their ecological role, either in Archaea or Bacteria, is similar since these biopolymers are involved in cell protection to fight against harsh environmental conditions [24], and in niche colonization; for example exo-cellular polymers are key players in biofilm formation $[22,36]$. In addition, some of these bacterial biopolymers are receiving renewed interest due to their biological functions, particularly their involvement in human health $[37,55]$.

Most bacteria are often covered by a layer of polysaccharides which is called glycocalyx [21]. These polymers can be linked to the cell surface by means of covalent bonds forming a capsule and therefore they are named capsular polysaccharides (CPS). Other polymers are weakly attached to the surface, or are totally released into the surrounding environment, forming slime, and they are referred as exopolysaccharides (EPS). This classification, according to cell location, is not clear [63] and more precise definitions have been collected in the literature [6]. For practical purposes, in the context of this article we will use the term EPS for both exo-cellular layers. In fact, these two types of EPS are carbohydrate polymers built from a reduced number of different monosaccharides (most common: glucose, fructose, galactose, rhamnose and fucose). However the presence of different isomers, linkage types and organic and inorganic monosaccharide substituents that could be combined in repeating units which have, as well, different degrees of polymerization and branching patterns, render a great variety of bacterial EPS. In another practical classification, bacterial EPS are divided into two main groups depending on whether a single monosaccharide type 
is present in the polymer or more; they are the homopolysaccharides (HoPS) and heteropolysaccharides (HePS), respectively, which also differ in the number of enzymes and organization of genes involved in their synthesis $[6,56,62]$. Finally, depending on the substituents present in the repeating units of HePS, there are non-charged, charged or neutral polymers. Within the latter, of special mention are the "zwitterionic" EPS characterized to have both positively (e.g. free amine) and negatively (e.g phosphate or carboxylate) charged moieties within their repeating units [37]. These molecules have been reported to be able to modulate the immune system, both innate and adaptive response, although they are very rare among bacteria. To date, only two Grampositive pathogens, Streptococcus pneumoniae and Staphylococcus aureus, as well as the Gramnegative Bacteriodes fragilis, a common member of the human intestinal microbiota, were reported as producers of such EPS [36]. Indeed, it has been indicated that the zwitterionic EPS, named polysaccharide A, from Bact. fragilis could play a key role in oral tolerance and in balancing the immune status associated with some infections or inflammatory disorders [50, 51, 52].

Some strains of Gram-positive bacteria such as Lactobacillus, a member of lactic acid bacteria (LAB) group, and Bifidobacterium are considered probiotics; that is "live microorganisms which when administered in adequate amounts confer a health benefit on the host" [15]. Worldwide, research on probiotics is one of the most interesting scientific fields due to its implication on human health, also representing a good opportunity for the industrial development of new products [3]. Some bifidobacteria and lactobacilli species share common habitats, for example animal mucosa such as the oral-gastrointestinal tract $[34,73]$. However, the genomic $\mathrm{G}+\mathrm{C}$ content separates Bifidobacterium $(\mathrm{G}+\mathrm{C}>50 \%)$ and Lactobacillus $(\mathrm{G}+\mathrm{C}<50 \%)$ in two taxonomic phyla: Actinobacteria and Firmicutes, respectively [16, 34, 66]. Nowadays, the capability of lactobacilli to synthesize EPS is well documented; in fact, some strains isolated from foods have been used for the manufacture of fermented dairy products from a long time ago [55]. The research interest in bifidobacterial EPS is more recent and there are data in literature that attribute some of the beneficial health effects produced by probiotic lactobacilli and bifidobacteria to their EPS. 
Therefore, in this article we will review some traits of the EPS-producing phenotype in LAB and bifidobacteria and we will gather, as well, evidence that could give us clues to understand the capability of EPS to modulate immune response.

\subsection{Biosynthesis of EPS from LAB}

To date, a wide variety of EPS synthesized by LAB belonging to both HoPS and HePS types have been described (for greater comprehension, read $[55,56])$. The HoPS are composed either of D-glucose ( $\alpha$-glucans and $\beta$-glucans) or D-fructose ( $\beta$-fructans), which can be divided into subtypes depending on the position of the carbon involved in linkage. The synthesis of $\alpha$-glucans and $\beta$ fructans requires the presence of sucrose as substrate, which donates the corresponding glycosyl moiety to a polymer in formation in a reaction catalyzed by a single type of enzyme named glycansucrase $[39,72]$. These extracellular enzymes are members of the glycoside hydrolase (GH) family, and are referred to as glucansucrases (family GH70) and fructansucrases (family GH68) involved in the polymerization of $\alpha$-glucans and $\beta$-fructans, respectively. They can also catalyze the hydrolysis of sucrose and the synthesis of oligosaccharides when the acceptor molecule is other than glycans [28]. $\beta$-glucans are less frequent in LAB and, to date, the few that have been described have the same structure: $(1 \rightarrow 3)-\beta$-D-glucan with side ramifications of a single $(1 \rightarrow 2)$-linked $\beta$-Dglucose. These $\beta$-glucans are synthesized through a different mechanism in which another single enzyme type (glucosyltransferase), that does not use sucrose as substrate, is involved [11, 75, 76]. This enzyme belongs to the COG1215 membrane-bound glycosyltransferase family and topology predictions show that a conserved cytosolic domain is flanked by two and four transmembrane segments [76]. The sequences of the glucosyltransferases from a few LAB are homologous to that of the polysaccharide synthase (GenBank accession no. CAB51329) from S. pneumoniae serotype 37 which produce the same structural capsular $\beta$-glucan. In addition, by means of agglutination experiments using pneumococci serotype 37 anti-serum, the presence of this type of polymer was detected in some LAB $[75,76]$ as well as in propionibacteria $[8,11]$. However, the mechanism of 
$\beta$-glucan synthesis by LAB is still not known; in Propionibacterium freudenreichii it seems that the homologous polysaccharide-synthase enzyme catalyzes the intracellular polymerization of glucose monomers, from nucleotide sugar precursors, and is able to carry out the export [8].

HePS from LAB result from the polymerization of repeating units which are composed of monosaccharides and of organic- and inorganic-substituted monosaccharides. Most common sugars are D-glucose, D-galactose and L-rhamonose and, to a lesser extent, N-acetyl-glucosamine and Nacetyl-galactosamine [56]. Fucose and ribose have been described in the repeating units of a few HePS [12, 33] and organic and inorganic molecules can also be present, for example, glucuronic acid [49], acetyl [71], glycerol-phosphate [78] and phosphate [70]. At the time of writing, combinations of 2 to 8 monomers have been described rendering more than 45 different structural repeating units determined by means of nuclear magnetic resonance (NMR) techniques. These different NMR structures are obtained from the variation in monomers, linkage type ( $\alpha$ or $\beta$ ), position of the carbon involved in linkage, presence of different side chains, etc. [56, 58]. The complexity of the chemical and structural composition of the HePS repeating units is reflected in the organization of genes encoding proteins involved in their synthesis, which are organized in eps clusters. In general, eps clusters from LAB have an operon structure with most genes oriented in one direction and having a high coding density and a highly conserved structural-functional organization. In general, LAB-eps clusters harbour genes coding for glycosyltransferases (GTF), which build the HePS repeating units, and proteins involved in the export-polymerization of the repeating units, in the HePS chain length determination, and in regulation of the full HePS biosynthesis process. Very often, mobile elements are located bordering these eps-clusters, which could explain the instability of HePS-production phenotype in some LAB [5, 10, 23, 56].

\subsection{Biosynthesis of EPS from Bifidobacterium genus}

The EPS-production phenotype has been less studied in bifidobacteria than in LAB, probably due to the lack of known technological use for bifidobacterial polymers. However, in the 
context of probiotics, research in EPS field is gaining interest since these polymers, as components of bacterial envelope, could be directly related with probiotic-host interactions, and therefore with a potential health benefit. Indeed, the first question to arise is whether bifidobacteria and non-food origin lactobacilli are able to synthesise EPS. Using culture-dependent techniques and a combination of phenotypic and genotypic screening, our group has demonstrated that lactobacilli and bifidobacteria from human origin (faeces) harbour eps genes and they are able to produce HePS under laboratory conditions [53, 59]. Similar results have recently been reported with another collection of bifidobacteria from human origin [46]. On the contrary, and as far as we know, synthesis of HoPS-type polymers have not been reported yet in strains of these genera isolated from human sources. Nevertheless, lactobacilli species isolated from duck and pig intestines were able to produced both glucan and fructan HoPS-types from sucrose [64]. By using animal models, it was inferred that HePS could be synthesised in vivo under the gastrointestinal conditions, either by lactobacilli or bifidobacteria [7, 14, 29]. Finally, a recent in silico analysis of bifidobacterial genomes underlines the ubiquitous presence of genes involved in the synthesis of HePS, which seems to be organized in cluster-like structures $[30,58]$. However, the remaining, and challenging, task is to purify the in vivo synthesised EPS in order to understand their physico-chemical properties, which could help to answer why only some specific polymers have biological and functional properties.

Up to now, only a few bifidobacterial polymers have been purified and fully characterised [58]. The EPS described in bifidobacteria are HePS-type, their monosaccharide constituents being those found for LAB-EPS; that is, glucose, galactose and rhamnose (Table 1). In B. animalis subsp. lactis, 3 out of 4 strains showed polymers with the same glucose- galactose- rhamnose ratio (about 2.5: 2: 1, respectively). Only the EPS synthesised by strain IPLA-R1 was different, since the rhamnose content increased; this was due to the production of another EPS-fraction of high molecular weight (HMW, about $3 \times 10^{6} \mathrm{Da}$ ) having $50 \%$ of rhamnose in its repeating unit structure [31]. The strain IPLA-R1, also named A1dOxR, was obtained from strain A1 by adaptation to 
increasing concentrations of bile salts in our laboratory, followed by successive sub-cultivations without selective agent. Indeed we have proved that bile salts trigger the synthesis of EPS in this species [54]. The production of more than one EPS-fraction was also detected in $B$. breve NCIMB8807 cultivated in milk, which synthesised two polymers differing in size (EPS $1=1.2 \times 10^{6}$ Da and EPS $2=6.4 \times 10^{5} \mathrm{Da}$ ) and in monosaccharide composition [46]. Similar to B. animalis subsp. lactis, the EPS synthesised by several strains of $B$. pseudocatenulatum showed similar monosaccharide ratio and composition (Table 1). In contrast, EPS synthesised by B. longum strains showed a wide distribution in their monosaccharide ratio. Galactose and glucose were present in most of them in variable proportions, with the exception of EPS synthesised by strain YIT4028; whereas, rhamnose was detected in half of the B. longum HePS (Table 1). In this regard, it was found that this monosaccharide was present in $48 \%$ of the HePS characterised from bifidobacteria to date. We have previously reported that the rhamnose content in EPS synthesised by lactobacilli and bifidobacteria of human origin was higher than in EPS synthesised by LAB strains of food origin: $52 \%$ in 21 human-origin EPS and $28 \%$ in 25 food-origin EPS [59]. Besides, to date only two described LAB- or bifido-polymers have an unusually high rhamnose content in their structural repeating unit, as determined by NMR technique; these are the heptasaccharide synthesised by Lactobacillus rhamnosus RW-9595M [69] and the HMW hexasaccharide synthesised by $B$. animalis subsp. lactis IPLA-R1 [31]. However, to the best of our knowledge, the biological relevance that a high rhamnose content in HePS from non-food origin could have, is still unknown.

\section{Immune modulation of EPS from LAB and bifidobacteria}

Apart from the ecological relevance that EPS may have for the producing bacteria and their industrial applications, there is increasing evidence to suggest a role for bifido- and LAB-EPS in the interaction between producing-bacteria and the (human) host, and therefore, exerting an impact on human health. It has been claimed that some EPS reduce cholesterol levels, act as fermentable (prebiotic) substrates for intestinal microbiota and modulate the immune response [55]. However, it 
is well known that not all EPS are able to improve the technological properties of fermented foods

[20] or to promote health benefits [2]. Therefore, the physico-chemical characteristics of EPS must be the key parameters determining their biological and functional properties.

Several works in literature report the ability of EPS synthesised by LAB and bifidobacteria to elicit immune responses (Table 2). In an attempt to correlate some physico-chemical traits of EPS with their immune-modulating capability, we have detected two association patterns. First, it seems that acidic HePS, which are characterised as having phosphate (i.e. negative charge) in their composition, are good inducers of the immune response. This fact was illustrated by the HePS synthesised by LAB used as starters in the dairy food industry, such as the strain Lactococcus lactis subsp. cremoris KSV20 involved in the manufacture of the Scandinavian fermented milk viili. The viilian-HePS was able to induce the synthesis of IFN $\gamma$ and IL-1 $\alpha$ in mouse spleen macrophages cultivated in vitro [25]. The repeating unit of KSV20 HePS is a pentasaccharide composed of glucose- galactose- rhamnose in ratio 2:2:1, with the side-chain $\alpha$-D-galactopyranose substituted with $\mathrm{PO}_{4}{ }^{-}$[42]. Similarly, Lb. delbrueckii subsp. bulgaricus OLL-1073-R1 synthesises an HePS composed of two fractions, acidic and neutral, both containing glucose and galactose (ratio 3:2) but the acid-fraction additionally having $0.1 \% \mathrm{PO}^{-}$[67]. The acid fraction was a strong inducer of proliferation and activity of different macrophages, whereas the neutral-fraction was not able to elicit stimulation [26, 44]. Furthermore, the same authors have proved that phosphate was the molecule triggering the immune response, since the chemical dephosphorylation of this HePS encompasses a reduction in the stimulatory effect [26]. The relevant role of $\mathrm{PO}_{4}{ }^{-}$in immune stimulation was also proven using the $\alpha$-glucan HoPS (dextran) synthesised by Leuconostoc mesenteroides as a model. When dextran was chemically phosphorylated, the proliferation of lymphocyte subsets from the murine spleen, as well as the gene expression of IFN $\gamma$ and IL-10, directly augmented with the phosphate content [61]. 
seem to act as suppressors of the immune response (Table 2). One of the first examples illustrating this fact was reported by Yasuda and co-workers [79] using Lactobacillus casei Shirota as a model. This strain harbours an eps-cluster of 10 genes which is involved in the synthesis of a HMW (cellwall) polysaccharide; knockout-mutants of eps genes were able to induce the production of TNF $\alpha$, IL-12, IL-10 and IL-6, by mouse macrophage (RAW-264.7) cell line or by mouse spleen cells, to a higher extent than the wild-type bacterium. Thus, the authors concluded that the EPS synthesised by L. casei Shirota act by reducing excessive reaction of immune cells not only against its own stimulating components, but also against other inducers such as LPS. Similarly, murin peritoneal macrophages stimulated with the HMW-EPS-producing L. rhamnosus RW-9595M, an isogenic variant of the strain ATCC9595, induced low levels of TNF $\alpha$ and IL-6; whereas, the parental $L$. rhamnosus ATCC9595 strain induced high levels of TNFa, IL-6 and IL-12 and showed decreased IL-10 production [4]. We have also detected immune suppression upon human peripheral blood mononuclear cells (PBMC) induced by the HMW-EPS-producing Lactobacillus paraplantarum BGCG11, in comparison with its isogenic EPS $^{-}$mutants [43]. Recently, Fanning and co-workers [14] reported similar behavioural patterns in Bifidobacterium genus, using the approach of wild / KO-mutants of B. breve UCC2003 in murin in vitro and in vivo models. Naïve spleen cells stimulated with the $\mathrm{EPS}^{+}$(wild strain) had significantly lower levels of pro-inflammatory cytokines (IFN $\gamma, \mathrm{TNF} \alpha$ and IL-12) compared with those of the isogenic B. breve EPS ${ }^{-}$mutants. Additionally, the type and percentage of immune spleen cells examined from mice fed with the $\mathrm{EPS}^{+}$strain were similar to that of untreated mice. On the contrary, mice fed with EPS $^{-}$strains increased the number and the percentage of different immune-subset cells in comparison with untreated mice. The expression of the cytokines produced by these cells also differed among the mice groups (feed placebo, $\mathrm{EPS}^{+}$or $\mathrm{EPS}^{-}$). The authors concluded that the strain B. breve UCC2003, which synthesises an EPS, whose physico-chemical composition has not been reported yet but seems to have big size, was able to evade some adaptive B-cell responses. 
The studies indicated above report the immune effect of the EPS-producing bacteria, but

only a few works have effectively demonstrated the ability of purified HePS to elicit immune response. Our group has recently shown that human PBMC cultivated in the presence of EPS isolated from 10 bifidobacteria strains display specific cytokine profiles; that is, chemically different EPS were able to elicit different immune responses [32]. Especially relevant are the results obtained with the HePS purified from the three closely related B. animalis subsp. lactis strains mentioned above: A1 (parental), A1dOx (bile-adapted derivative) and A1dOxR (bile-adapted derivative having ropy phenotype). The EPS A1dOxR (at $1 \mu \mathrm{g} / \mathrm{ml}$ ) elicited lower production of cytokines by human PBMC than the EPS A1 or A1dOx, therefore suggesting an immunesuppressive profile of the former. Additionally, when these HePS-producing B. animalis subsp. lactis strains were co-cultivated with colonocyte-like cells (Caco2) they elicited different cytokine patterns (unpublished results, Figure 1). The ropy A1dOxR strain induced significantly lower levels of pro-inflammatory IL-6 and IL-8 cytokines than the control (Caco2 cultivated in DMEM), whereas A1 induced the secretion of elevated amounts of these molecules, suggesting an immune activating role of the parental strain. On the other hand, Caco2 cells did not modify significantly IL$1 \beta$ production after culture with any bacterial strain; however, treatment with $\mathrm{A} 1$ and $\mathrm{A} 1 \mathrm{dOx}$ showed a tendency to decrease its levels whereas an inverse trend was observed with A1dOxR, the production being significantly higher when compared with the other two strains. Given the relevance of IL-1 $\beta$ in the generation of Th17 cells, involved in mucosal defence and Treg/Th17 plasticity, these data could suggest a role of the ropy A1dOxR strain in the immune homeostasis in the gut. In this regard, the EPS A1dOxR is a polymer composed of three EPS-fractions of different size: HMW $\left(3.5 \times 10^{6} \mathrm{Da}\right)$, middle weight $\left(3.0 \times 10^{4} \mathrm{Da}\right)$ and low weight $\left(4.9 \times 10^{3} \mathrm{Da}\right)$ [31]; whereas, the other two related EPS (A1 and A1dOx) lack the HMW fraction [57]. Therefore, it seems that the presence of the HMW fraction could be responsible for the immune suppression capability of EPS A1dOxR. In this regard, the findings of Bleau and co-workers [4] also reinforce this idea since intermediate polymer chains (16-30 units, molecular weight $\left.<10^{4} \mathrm{Da}\right)$ obtained after hydrolysis of 
the HMW-EPS (size $5.3 \times 10^{5}$ Da) RW-9595M showed increased production of IL-10 by macrophages, in comparison with the native polymer synthesised by L. rhamnosus. It is worth noting that another common trait between the HMW-EPS A1dOxR (from B. animalis subsp. lactis) and the native EPS RW-9595M (from L. rhamnosus) is the high presence of rhamnose (more than $50 \%)$ in the composition of their repeating units [31, 69]. At the moment, it is unknown if this characteristic could also be relevant to regulate the immune response.

Finally, some works have been carried out regarding the immune activity of $\beta$-glucans (HoPS-type) produced by LAB [17] and Propionibacterium; this last genus belonging to Actinobacteria phylum, as bifidobacteria, and specific species are relevant for the sensorial properties of some cheeses [9]. Bacterial $\beta$-glucans, which have a common structure of branched $(1 \rightarrow 3)-\beta$-D-glucose substituted at $\mathrm{C} 2$ with $\beta$-D-glucose (Table 2 ), act by modifying the response of PBMC since it seems that KO-mutants are able to relieve the immune suppression elicited by the wild type strains. Similarly, $\beta$-glucans from fungus Sclerotium, having the same monomer composition, but differing in size and spatial conformation, are able to elicit variable proliferation in human monocyte cultures [13]. Therefore, it seems that the size of EPS polymers, either HePS or HoPS is of special relevance for their immune properties.

Information about immune mechanism(s) elicited by bacterial EPS at molecular level is still scarce and, as far as we know, at present it is unknown for bifido- or LAB-EPS. In relation with other microbial EPS, it seems that some fungi glucuronoxylomannans (GXM) interact with the immune system through different Toll-like Receptors (TLR), also inducing production of nitric oxide by phagocytes [18]. In these fungal EPS the diameter of the molecule may potentially influence the inflammatory response against the GXM-producing fungi Cryptococcus [18, 80], as previously stated for Sclerotium $\beta$-glucans [13]. Regarding bacteria, it has recently been demonstrated that the zwitterionic polysaccharide A (or PSA) produced by Bact. fragilis can suppress in vivo the pro-inflammatory IL-17 production by intestinal immune cells induced by Helicobacter hepaticus [35]. This PSA has the ability to induce Foxp $3^{+} \mathrm{T}_{\text {reg }}$ cells, which produce an 
increase of anti-inflammatory cytokines such as IL-10, and it seems that this induction is mediated

by TLR-2 [51]. These authors propose that the immune system can discriminate between pathogens and predominant members of the commensal microbiota via recognition of molecules such as EPS [52]. Based on our findings and those reported in the literature, we propose a hypothetical mechanism(s) of action for HMW-EPS synthesized by bifidobacteria (Figure 2). The presence of HMW-EPS A1doXR at the mucosal surfaces could induce the generation of dendritic cells with a tolerogenic function by different mechanisms, not well known, but which could include the production of specific cytokines. These tolerogenic dendritic cells also secreted immunosuppressive cytokines and then the resultant cytokine network could mediate the induction and/or the expansion of regulatory $\mathrm{T}$ cells (probably $\mathrm{FOXP} 3^{+} \mathrm{CD} 25^{\text {high }} \mathrm{T}_{\text {reg }}$ ) which in turn will control an excessive effector $\mathrm{T}$ cell $\left(\mathrm{T}_{\mathrm{eff}}\right)$ response or, in the presence of a specific cytokine environment, might transdifferentiate into Th17 cells, thus maintaining mucosal defence and homeostasis.

\section{Conclusion}

In summary, base on literature data we propose that EPS having negative charge (phosphate in its composition) and/or having small size are able to act as mild stimulators of different immune cells; whereas, neutral and big-size (near $10^{6} \mathrm{Da}$ ) polymers have a suppressive profile, or could attenuate an excessive response, thus helping the producing bacteria to evade the immune response of the host. Nevertheless, although there is some evidence supporting this hypothesis, further research is needed in order to demonstrate which are the key physico-chemical parameters determining the ability of bifido- and LAB-EPS to modulate the immune response. Also, the mechanism(s) of action through the putative mediation of Foxp $3^{+} \mathrm{T}_{\text {reg }}$ cells induction, or whether other pathways could be plausible, deserves further investigation.

\section{Acknowledgements}


Union) and the Spanish "Plan Nacional I+D+I" from the "Ministerio de Ciencia e Innovación"

(MICINN) through the project AGL2009-09445. C. Hidalgo-Cantabrana acknowledges his FPI

fellowship and P. López her research contract, supported by project AGL2010-14952, both from

MICINN.

\section{References}

1. Abbad-Andaloussi S, Talbaoui H, Marczak R, Nonay R (1995) Isolation and characterization of exocellular polysaccharides produced by Bifidobacterium longum. Appl Microbiol Biotechnol 43:995-1000

2. Amrouche T, Boutin Y, Prioult G, Fliss I (2006) Effects of bifidobacterial cytoplasm, cell wall and expolysaccharide on mouse lymphocyte proliferation and cytokine production. Int Dairy $\mathbf{J}$ $16: 70-80$

3. Arboleya S, Salazar N, Ruas-Madiedo P, de los Reyes-Gavilán CG, Gueimonde M (2012) Development of probiotic products for nutritional requirements of specific human population. Eng Life Sci 12 (first published on-line 23, May DOI: 10.1002/elsc.201100129)

4. Bleau C, Monges A, Rashidan K, Laverdure J-P, Lacroix M, Van Calsteren M-R, Millette M, Savard R, Lamontagne L (2010) Intermediate chains of exopolysaccharides from Lactobacillus rhamnosus RW-9595M increase IL-10 production by macrophages. J Appl Microbiol 108:666675

5. Broadbent JR, McMahon DJ, Welker DL, Oberg CJ, Moineau S (2003) Biochemistry, genetics, and applications of exopolysaccharide production in Streptococcus thermophilus: a review. J Dairy Sci 86:407-423

6. Cescutti P (2009) Bacterial capsular polysaccharides and exopolysaccharides. In: Moran A, Holst, O, Brennan PJ, von Itzstein M (eds) Microbial glycobiology. Structures, relevance and applications. Academic Press (Elsevier), London, UK, pp 93-108 
7. Denou E, Pridmore RD, Berger B, Panoff JM, Arigoni F, Brüssow H (2008) Identification of genes associated with the long-gut-persistence phenotype of the probiotic Lactobacillus johnsonii strain NCC522 using a combination of genomic and transcriptomic analysis. J Bacteriol 190:3161-3168

8. Deutsch S-M, Le Bivic P, Hervé C, Madec M-N, LaPointe G, Jan G, Le Loir Y, Falentin H (2010) Correlation of the capsular phenotype in Propionibacterium freudenreichii with the level of expression of gtf, a unique polysaccharide synthase-encoding gene. Appl Environ Microbiol $76: 2740-2746$

9. Deutsch S-M, Parayre S, Bouchoux A, Guymarc'h F, Dewulf J, Dols-Lafargue M, Baglinier F, Cousin FJ, Falentin H, Jan G, Foligné B (2012) Contribution of surface $\beta$-glucan polysaccharide to physicochemical and immunomodulatory properties of Propionibacterium freudenreichii. Appl Environ Microbiol 78:1765-1775

10. De Vuyst L, Weckx S, Ravyts F, Herman L, Leroy F (2011) New insights into the exopolysaccharide production of Streptococcus thermophilus. Int Dairy J 21:586-591

11. Dols-Lafarge M, Lee HY, Le Marrec C, Heyraud A, Chambat G, Lonvaud-Funel A (2008) Characterization of $g t f$, a glucosyltransferase gene in the genomes of Pediococcus parvulus and Oenococcus oeni, two bacterial species commonly found in wine. Appl Environ Microbiol $74: 4079-4090$

12. Faber EJ, van Haaster DJ, Kamerling JP, Vliegenthart JFG (2002) Characterization of the exopolysaccharide produced by Streptococcus thermophilus 8S containing an open chain nononic acid. Eur J Biochem 269:5590-5598

13. Falch BH, Espevik T, Ryan L, Stokke B (2000) The cytokine stimulating activity of $(1 \rightarrow 3)-\beta-D-$ glucans is dependent on the triple helix conformation. Carbohyd Res 329:587-596.

14. Fanning S, Hall LJ, Cronin M, Zomer A, MacSharry J, Goulding D, O’Connell-Motherway M, Shanahan F, Nally K, Dougan G, van Sinderen D (2012) Bifidobacterial surface- 
expolysaccharide facilitates commensal-host interaction through immune modulation and pathogen protection. Proc Natl Acad Sci USA 109:2108-2113

15. FAO/WHO (2006) Probiotics in food. Health and nutritional properties and guidelines for evaluation. FAO Food and Nutritional paper No. 85 (ISBN 92-5-105513-0)

16. Felis GE, Dellaglio F (2007) Taxonomy of lactobacilli and bifidobacteria. Curr Issues Intest Microbiol 8:44-61

17. Fernández de Palencia P, Werning ML, Sierra-Filardi E, Dueñas MT, Irastorza A, Corbí A, López P (2009) Probiotic properties of the 2-subtitued (1,3)- $\beta$-glucan-producing bacterium Pediococcus parvulus 2.6. Appl Environ Microbiol 75:4887-4891

18. Fonseca FL, Nohara LL, Cordero RJB, Frases S, Casadevall A, Almeida IC, Nimrichter L, Rodrigues ML (2010) Immunomodulatory effects of serotype B glucuronoxylomannan from Cryptococcus dattii correlate with polysaccharide diameter. Infect Immu 78:3861-3870

19. Habu Y, Nagaoka M, Yokokura T, Azuma I (1987) Structural studies of cell wall polysaccharides from Bifidobacterium breve YIT 4010 and related Bifidobacterium species. J Biochem 102:1423-1432

20. Hassan AN (2008) Possibilities and challenges of exopolysaccharide-producing lactic cultures in dairy foods. J Dairy Sci 91:1282-1298

21. Holst O, Moran AP, Brennan PJ (2009) Overview of the glycosylated components of the bacterial cell envelope. In: Moran A, Holst, O, Brennan PJ, von Itzstein M (eds) Microbial glycobiology. Structures, relevance and applications. Academic Press (Elsevier), London, UK, pp 3-13

22. Jeon JG, Rosalen PL, Falsetta ML, Koo H (2011) Natural products in caries research: current (limited) knowledge, challenges and future perspective. Caries Res 45:243-263.

23. Jolly L, Stingelle F (2001) Molecular organization and functionality of exopolysaccharide gene clusters in lactic acid bacteria. Int Dairy J 11:733-745 
24. Khan S, Mukherjee A, Chandrasekaran N (2011) Silver nonoparticles tolerant bacteria from sewage environment. Environ Sci (China) 23:346-352

25. Kitazawa H, Itoh T, Tamioaka Y, Mizugaki M, Yamaguchi T (1996) Induction of IFN- $\gamma$ and IL$1 \alpha$ production in macrophages stimulated with phosphopolysaccharide produced by Lactococcus lactis ssp. cremoris. Int J Food Microbiol 31:99-106

26. Kitazawa H, Harata T, Uemura J, Saito T, Kaneko T, Itoh T (1998) Phosphate group requirement for mitogenic activation of lymphocytes by an extracellular phosphopolysaccharide from Lactobacillus delbrueckii ssp. bulgaricus. Int J Food Microbiol 40:169-175

27. Kohno M, Suzuki S, Kanaya T, Yoshino T, Matsuura Y, Asada M, Kitamura S (2009) Structural characterization of the extracellular polysaccharide produced by Bifidobacterium longum JBL05. Carbohydr Polym 77:351-357

28. Korakli M, Vogel RF (2006) Structure/function relationship of homopolysaccharides produced glycansucrases and therapeutic potential for their synthesized glycans. Appl Microbiol Biotechnol 71:790-803

29. Lebeer S, Claes IJJ, Verhoeven TLA, Vanderleyden J, De Keersmaecker SCJ (2010) Exopolysacchrides of Lactobacillus rhamnosus GG form a protective shield against innate immune factors in the intestine. Microb Biotechnol 4:368-374

30. Lee JH and O’Sullivan DJ (2010) Genomic insights into bifidobacteria. Microbiol Mol Biol Rev $74: 378-416$

31. Leivers S, Hidalgo-Cantabrana C, Robinson G, Margolles A, Ruas-Madiedo P, Laws AP (2011) Structure of the high molecular weight exopolysaccharide produced by Bifidobacterium animalis subps. lactis IPLA-R1 and sequence analysis of its putative eps cluster. Carbohydr Res $346: 2710-2717$

32. López P, Monteserín DC, Gueimonde M, de los Reyes-Gavilán, CG, Margolles A, Suárez A, Ruas-Madiedo P (2012) Exopolysaccharide-producing Bifidobacterium strains elicit different in vitro responses upon interaction with human cells. Food Res Int 46:99-107 
33. Low D, Ahlgren JA, Horne D, McMahon DJ, Oberg CJ, Broadbent JR (1998) Role of Streptococcus thermophilus MR-1C capsular exopolysaccharide in cheese moisture retention. Appl Environ Microbiol 64:2147-2251

34. Margolles A, Mayo B, Ruas-Madiedo P (2009) Screening, identification and characterization of Lactobacillus and Bifidobacterium strains. In: Lee YK, Salminen S (eds) Handbook of probiotics and prebiotics, $2^{\text {nd }}$ edn. Wiley \& Sons, Inc, New Jersey, USA, pp 4-24

35. Mazmanian S, Round JL, Kasper DL (2008) A microbial symbiosis factor prevents intestinal inflammatory disease. Nature 453:620-625

36. McDougald D, Rice SA, Barraud N, Steinberg PD, Kjelleberg S (2012) Should we stay or should we go: mechanisms and ecological consequences for biofilm dispersal. Nature Rev Microbiol 10:39-50.

37. McLoughlin RM, Kasper DL (2009) Immunomodulation by zwitterionic polysaccharides. In: Moran A, Holst, O, Brennan PJ, von Itzstein M (eds) Microbial glycobiology. Structures, relevance and applications. Academic Press (Elsevier), London, UK, pp 957-980

38. Moran A, Holst, O, Brennan PJ, von Itzstein M (2009) Microbial glycobiology. Structures, relevance and applications. Academic Press (Elsevier), London, UK

39. Monsan P, Bozonnet S, Albenne C, Joucla G, Willemot RM, Remaud-Siméon M (2001) Homopolysaccharides fom lactic acid bacteria. Int Diary J 11:675-685

40. Nagaoka M, Hahimoto S, Shibata H, Kimura I, Kimura K, Sawada H, Yokokura T (1996) Structure of a galactan from cell walls of Bifidobacterium catenulatum YIT4016. Carbohydr Res 281:285-291

41. Nagaoka M, Shibata H, Kimura I, Hashimoto S, Kimura K, Sawada H, Yokokura T (1995) Structural studies on a cell wall polysaccharide from Bifidobacterium longum YIT4028. Carbohydr Res 274:245-249 
42. Nakajima H, Hirota T, Toba T, Itoh T, Adachi S (1992) Structure of extracellular polysaccharide from slime-forming Lactococcus lactis subsp. cremoris SBT 0495. Carbohydr Res 224:245-253

43. Nikolic M, López P, Strahinic I, Suárez A, Kojic M, Fernández-García M, Topisirovic L, Golic N, Ruas-Madiedo P (2012) Characterization of the exopolysaccharide (EPS)-producing Lactobacillus paraplantarum BGCG11 and its non-EPS producing derivative strains as potential probiotics. Int J Food Microbiol 158:155-162

44. Nishimura-Uemura J, Kitazawa H, Kawai Y, Itoh T, Oda M, Saito T (2003) Functional alteration of mucrine macrophages stimulated with extracellular polysaccharides from Lactobacillus delbrueckii ssp. bulgaricus OLL1073R-1. Food Microbiol 20:267-273

45. Poli A, Di Donato P., Abbamondi GR, Nicolaus B (2011) Synthesis, production and biotechnological applications of exopolysaccharides and polyhydroxyalkanoates by archaea. Archaea Vol 2011, Article ID 693253: 1-13

46. Prasanna PHP, Grandison AS, Charalampopoulos D (2012) Screening human intestinal Bifidobacterium strains for growth, acidification, EPS production and viscosity potential in lowfat milk. Int Dairy J 23:36-44

47. Rehm BH (2010) Bacterial polymers: biosynthesis, modifications and applications. Nature Rev Microbiol 8:578-592

48. Roberts CM, Fett WF, Osman SF, Wijey C, O’Connor JV, Hoover DG (1995) Exopolysaccharide production by Bifidobacterium longum BB-79. J Appl Biotechnol 78:463468.

49. Rodríguez-Carvajal MA, Sánchez JI, Campelo AB, Martínez B, Rodríguez A, Gil-Serrano AM (2008) Structure of the high-molecular weight exopolysaccharide isolated from Lactobacillus pentosus LPS26. Carbohyd Res 343:3066-3070

50. Round JL, Mazmanian SK (2009) The gut microbiota shapes intestinal immune responses during health and disease. Nature Rev Microbiol 9:313-323 
51. Round JL, Mazmanina SK (2010) Inducible Foxp3+ regulatory T-cell development by a commensal bacterium of the intestinal microbiota. PNAS 107:12204-12209

52. Round JL, Lee SM, Li J, Tran G, Jabri B, Chatila TA, Mazmanian SK (2011) The Toll-like receptor 2 pathway established colonization by a commensal of the human microbiota. Science 322:974-977

53. Ruas-Madiedo P, Moreno JA, Salazar N, Delgado S, Mayo B, Margolles A, de los ReyesGavilán CG (2007) Screening of exopolysaccharide-producing Lactobacillus and Bifidobacterium strains isolated from the human intestinal microbiota. Appl Environ Microbiol $73: 4385-4388$

54. Ruas-Madiedo P, Gueimonde M, Arigoni F, de los Reyes-Gavilán CG, Margolles A (2009) Bile affects the synthesis of exopolysaccharides by Bifidobacterium animalis. Appl Environ Microbiol 75:1204-1207

55. Ruas-Madiedo P, Salazar N, de los Reyes-Gavilán CG (2009) Exopolysaccharides produced by lactic acid bacteria in food and probiotic applications. In: Moran A, Holst, O, Brennan PJ, von Itzstein M (eds) Microbial glycobiology. Structures, relevance and applications. Academic Press (Elsevier), London, UK, pp 887-902

56. Ruas-Madiedo P, Salazar N, de los Reyes-Gavilán CG (2009) Biosynthesis and chemical composition of expolysaccharides produced by lactic acid bacteria. In: Ullrich M (ed) Bacterial polysaccharides. Current innovations and futures trends. Caister Academic Press, Norfolk, UK, pp 279-310

57. Ruas-Madiedo P, Medrano M, Salazar N, de los Reyes-Gavilán CG, Pérez PF, Abraham AG (2010) Exopolysaccharides produced by Lactobacillus and Bifidobacterium strains abrogate in vitro the cytotoxic effect of bacterial toxins on eukaryotic cells. J Appl Microbiol 109:20792086

58. Ruas-Madiedo P, Sánchez B, Hidalgo-Cantabrana C, Margolles A, Laws A (2012) Exopolysaccharides from lactic acid bacteria and bifidobacteria. In: Hui YH, Evranuz EO (eds) 
Handbook of animal-based fermented food and beverage technology, $2^{\text {nd }}$ (Ed.) CRC Press, Florida, USA, pp 125-152

59. Salazar N, Prieto A, Leal JA, Mayo B, Bada-Gancedo JC, de los Reyes-Gavilán CG, RuasMadiedo P (2009) Production of exopolysaccharides by Lactobacillus and Bifidobacterium strains of human origin, and metabolic activity of the producing bacteria in milk. J Dairy Sci $92: 4158-4168$

60. Salazar N, Ruas-Madiedo P, Prieto A, Calle L, de los Reyes-Gavilán CG (2012) Characterization of exopolysaccharides produced by Bifidobacterium longum NB667 and its cholate-resistant derivative strain B667dCo. J Agric Food Chem 60:1028-1035

61. Sato T, Hishimura-Uemura J, Shimosato T, Kawal Y, Kitazawa H, Saito T (2004) Dextran from Leuconostoc mesenteroides augments immunostimulatory effects by the introduction of phosphate groups. J Food Prot 67:1719-1724

62. Sutherland IW (2001) Microbial polysaccharides from Gram-negative bacteria. Int Dairy J 11:663-674

63. Taylor CM, Roberts IS (2005) Capsular polysaccharides and their role in virulence. Contrib Microbiol 12:55-66

64. Tieking M, Kaditzky S, Valcheva R, Korakli M, Vogel RF, Gänzle MG (2005) Extracellular homonolysaccharides and oligosaccharides from intestinal lactobacilli. J Appl Microbiol 99:692-702

65. Tone-Shimura Y, Toida T, Kawashima T (1996) Isolation and structural analysis of polysaccharide containing galactofuranose from the walls of Bifidobacterium infantis. J Bacteriol 178:317-320.

66. Turroni F, Bottacini F, Foroni E, Mulder I, Kim JH, Zomer A, Sánchez B, Bidossi A, Ferrarini A, Giubellini V, Delledonne M, Henrissat B, Coutinho P, Oggioni M, Filzgerald GF, Mills D, Margolles A, Kelly D, van Sinderen D, Ventura M (2010). Genome analysis of Bifidobacterium 
bifidum PRL2010 reveals metabolic pathways for host-derived glycan foraging. Proc Natl Acad Sci USA 107:19514-19519

67. Uemura J, Itoh T, Kasneko T, Noda K (1998) Chemical characterization of extracellular polysaccharide from Lactobacillus belbrueckii subsp. bulgaricus OLL1073R-1. Milchwissenschaft 53:443-446

68. Ullrich M (2009) Bacterial polysaccharides. Current innovations and futures trends. Caister Academic Press, Norfolk, UK

69. van Calsteren MR, Pau-Roblot C, Be A, Roy D (2002) Structure determination of the exopolysaccharides produced by Lactobacillus rhamnosus strains RW-9595 and R, Biochem J $363: 7-17$

70. van Casteren WHM, Dijkema C, Schols HA, Beldman G, Voragen AGJ (1998) Characterization and modification of the exopolysaccharide produced by Lactococcus lactis subsp. cremoris B40. Carbohyd Polym 37:123-130

71. van Casteren WHM, de Waard P, Dijkema C, Schols HA, Voragen AGJ (2000) Structural characterization and enzymatic modification of the exopolysaccharide produced by Lactococcus lactis subsp. cremoris B891. Carbohyd Res 327:411-422

72. van Hijum SAFT, Kralj S, Ozimek LK, Dijkhuizen L, van Geel-Schutten IGH (2006) Structurefunction relationships of glucansucrase and fructansucrase enzymes from lactic acid bacteria. Microbiol Mol Biol Rev 70:157-176

73. Ventura M, Turroni F, Zomer A, Foroni E, Giubellini V, Bottacini F, Canchaya C, Claesson MJ, He F, Mantzourani M, Mulas L, Ferrarini A, Gao B, Delledonne M, Henrissat B, Coutinho P, Oggioni M, Gupta RS, Zhang Z, Beighton D, Fitzgerald GF, O'Toole PW, van Sinderen D. (2009) The Bifidobacterium dentium Bd1 genome sequence reflects its genetic adaptation to human oral cavity. PLoS Genet 5:e1000785 
74. Vinderola G, Perdigón G, Duarte J, Farnworth E, Matar C (2006) Effects of the oral administration of the exopolysaccharide produced by Lactobacillus kefiranofaciens on the gut mucosal immunity. Cytokine 36:254-260

75. Walling E, Girandeau E, Lonvaud-Funel A (2005) A putative glucan synthase gene dps detected in exopolysaccharides-producing Pediococcus damnosus and Oenococcus oeni strains isolated from wine and cider. Int J Food Microbiol 98:53-62.

76. Werning ML, Ibarburu I, Dueñas MT, Irastorza A, Navas J, López P (2006) Pediococcus parvulus gtf gene encoding the GTF glycosyltransferase and its application for specific PCR detection of $\beta$-D-glucan-producing bacteria in foods and beverages. J Food Prot 69:161-169

77. Wu M-H, Pan T-M, Wu Y-J, Chang S-J, Chang M-S, Hu C-Y. (2010) Exopolysaccharide activities from probiotic Bifidobacterium: inmmunomodulatory effects (on J774A.1 macrophages) and antimicrobial properties. Int J Food Microbiol 144:104-110

78. Yang Z, Staaf M, Huttunen E, Widmalm G (2000) Structure of a viscous exopolysaccharide produced by Lactobacillus helveticus K16. Carbodyd Res 329:465-469

79. Yasuda E, Serata M, Tomoyuki S (2008) Suppressive effect on activation of macrophages by Lactobacillus casei strain Shirota genes determining the synthesis of cell wall-associated polysaccharide. Appl Environ Microbiol 74:4746-4755

80. Zaragoza O, García-Rodas R, Nosanchuk JD, Cuenca-Estrella M, Rodríguez-Tudela JL, Casadevall A (2010) Fungal cell gigantism during mammanlian infection. PLoS Pathog 6:e1000945 (doi:10.1371/Journal.ppat.1000945)

81. Zdorovenko EL, Kachala VV, Sidarenka AV, Izhik AV, Kisileva EP, Shashkov AS, Novik GI, Knirel YA (2009) Structure of the cell wall polysaccharides of probiotic bifidobacteria Bifidobacterium bifidum BIM M-465. Carbohyd Res 344:2417-2420 


\section{Figure Legends}

Figure 1 Concentration (pg/ml) of some cytokines produced by Caco2 cells (in confluent and differentiated monolayer state) co-cultivated (for $8 \mathrm{~h}$ at $37^{\circ} \mathrm{C}, 5 \% \mathrm{CO}_{2}$ ) with three closely related $B$. animalis subsp. lactis strains (ratio Caco2: bacteria, 1: 10): A1 (white bar), A1dOx (light grey bar) and A1dOxR (dark grey bar). The black bar represents the control (Caco2 cultivated with DMEM antibiotic-free medium). The experimental design and material used was similar to that showed in Lopez and co-workers [32]. Cytokines were measure by means of ELISA tests (R\&D Systems Europe Ltd., UK) and values depicted are the mean and standard deviation of three independent coculture replicates. Data were analysed by means of one-way ANOVA (SPSS/PC 15.0 software package, SPSS Inc., USA). For each cytokine, differences $(\mathrm{p}<0.05)$ between each strain with respect to the control are represented by an asterisk; differences among the three strains were assessed by a mean comparison test LSD (less significant difference) and bars that do not share a common letter are significantly $(\mathrm{p}<0.05)$ different.

Figure 2 Hypothesis for immune suppression elicited by the high molecular weight (HMW)-EPS from B. animalis subsp. lactis $\mathrm{A} 1 \mathrm{dOxR}$. The capability to activate naïve $\mathrm{CD} 4^{+} \mathrm{T}$ cells through dendritic cells (DC) presenting EPS molecules has been demonstrated for specific ("zwitterionic”) polymers [50, 51, 52], although this way seems to be less plausible for non-charged EPS (a). In the B. animalis subsp. lactis strain, and in accordance with our preliminary in vitro [32] and in vivo (unpublished) data, the presence of HMW-EPS A1doXR could induce the activation and differentiation of $\mathrm{DC}$, resulting in a cytokine $(\mathrm{CK})$ production pattern that promote the generation of tolerogenic DC. This tolerogenic DC and the CK environment could mediate the differentiation of naïve T cells into regulatory $\mathrm{T}$ cells (probably FOXP $3{ }^{+} \mathrm{CD} 25^{\text {high }} \mathrm{T}_{\text {reg }}$ ) that would drive the control of an excessive effector $\mathrm{T}$ cells $\left(\mathrm{T}_{\text {eff }}\right)$ response or, in the presence of specific CK environment, might trans-differentiate into Th17 cells (b). Additionally, this strain was able to reduce the release of pro-inflammatory cytokines (Il-6 and IL-8) by enterocyte-like cells (c, Figure $1)$. 
Table 1 Main monosaccharides present in the HePS synthesised by the Bifidobacterium genus. Those present in LAB-HePS have been previously published [56].

\begin{tabular}{|c|c|c|c|c|c|c|}
\hline \multirow[b]{2}{*}{ Species } & \multirow[b]{2}{*}{ Strain } & \multicolumn{3}{|c|}{ Monosaccharide ratio } & \multirow[b]{2}{*}{ Repeated unit } & \multirow[b]{2}{*}{ Reference } \\
\hline & & Glc & Gal & Rha & & \\
\hline \multirow[t]{5}{*}{ B. animalis } & C64MRa & 2.5 & 1.5 & 1 & Unknown & [59] \\
\hline & E43 & 2.5 & 2 & 1 & Unknown & [59] \\
\hline & A1 & 2.5 & 2 & 1 & Unknown & [57] \\
\hline & IPLA-R1 (A1dOxR) & 1 & 1 & 1.5 & Unknown & [57] \\
\hline & HMW-IPLA-R1 ${ }^{\mathrm{a}}$ & 1 & 2 & 3 & Hexa-saccharide & {$[31]$} \\
\hline \multirow[t]{2}{*}{ B. bifidum } & BIM B-465 & 1.3 & 1 & & Hepta-saccharide & [81] \\
\hline & ALM35 & 1 & 3 & 2.4 & Unknown & {$[46]$} \\
\hline \multirow[t]{3}{*}{ B. breve } & YIT4010 & 1.5 & 1 & & Penta-saccharide & [19] \\
\hline & NCIMB8807-EPS1 & 2.5 & 1 & 1.4 & Unknown & [46] \\
\hline & NCIMB8807-EPS2 & 1 & 1.9 & & Unknown & {$[46]$} \\
\hline B. catenulatum & YIT4016 & & 1 & & Tri-saccharide & {$[40]$} \\
\hline B. longum subsp. longum & ATCC $15707^{\mathrm{T}}$ & 1 & 1 & & Unknown & [1] \\
\hline B. longum subsp. infantis & ATCC $15697^{\mathrm{T}}$ & b & 1 & & Di-saccharide & {$[65]$} \\
\hline \multirow{11}{*}{ B. longum } & YIT4028 & & 1.5 & 1 & Penta-saccharide & [41] \\
\hline & BB-79 & 1 & 1.5 & & Unknown & [48] \\
\hline & JBL05 & 2 & 4 & 1 & Hepta-saccharide & [27] \\
\hline & $\mathrm{H} 73$ & 2.5 & 1 & 2 & Unknown & [59] \\
\hline & L55 & 4 & 1 & 1 & Unknown & [59] \\
\hline & H67 & 4 & 1 & 4 & Unknown & [59] \\
\hline & $\mathrm{E} 44$ & 1 & 1 & & Unknown & [59] \\
\hline & CCUG52486 & 1.3 & 1 & & Unknown & [46] \\
\hline & NCIMB702205 & 1 & 2.5 & & Unknown & [46] \\
\hline & NB667 & 1 & 2.2 & 1 & Unknown & {$[60]$} \\
\hline & N667dCo & 1.2 & 2.3 & 1 & Unknown & [60] \\
\hline \multirow[t]{5}{*}{ B. pseudocatenulatum } & A102 & 2 & 1 & & Unknown & [59] \\
\hline & C52 & 1 & 1 & & Unknown & [59] \\
\hline & E515 & 2 & 1 & & Unknown & [59] \\
\hline & E63 & 1 & 1 & & Unknown & [59] \\
\hline & H34 & 1.5 & 1 & & Unknown & [59] \\
\hline
\end{tabular}

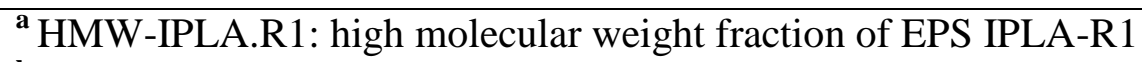

b backbone: $\rightarrow 3)-\beta$-D-Galf-(1 $\rightarrow 3)-\alpha-D-G a l p-(1 \rightarrow$, which are partially substituted at O- 6 with $\beta$-DGlcp. 
Table 2 Immune responses elicited by the EPS synthesised by bacteria present in foods (updated from Ruas-Madiedo et al., 2009b).

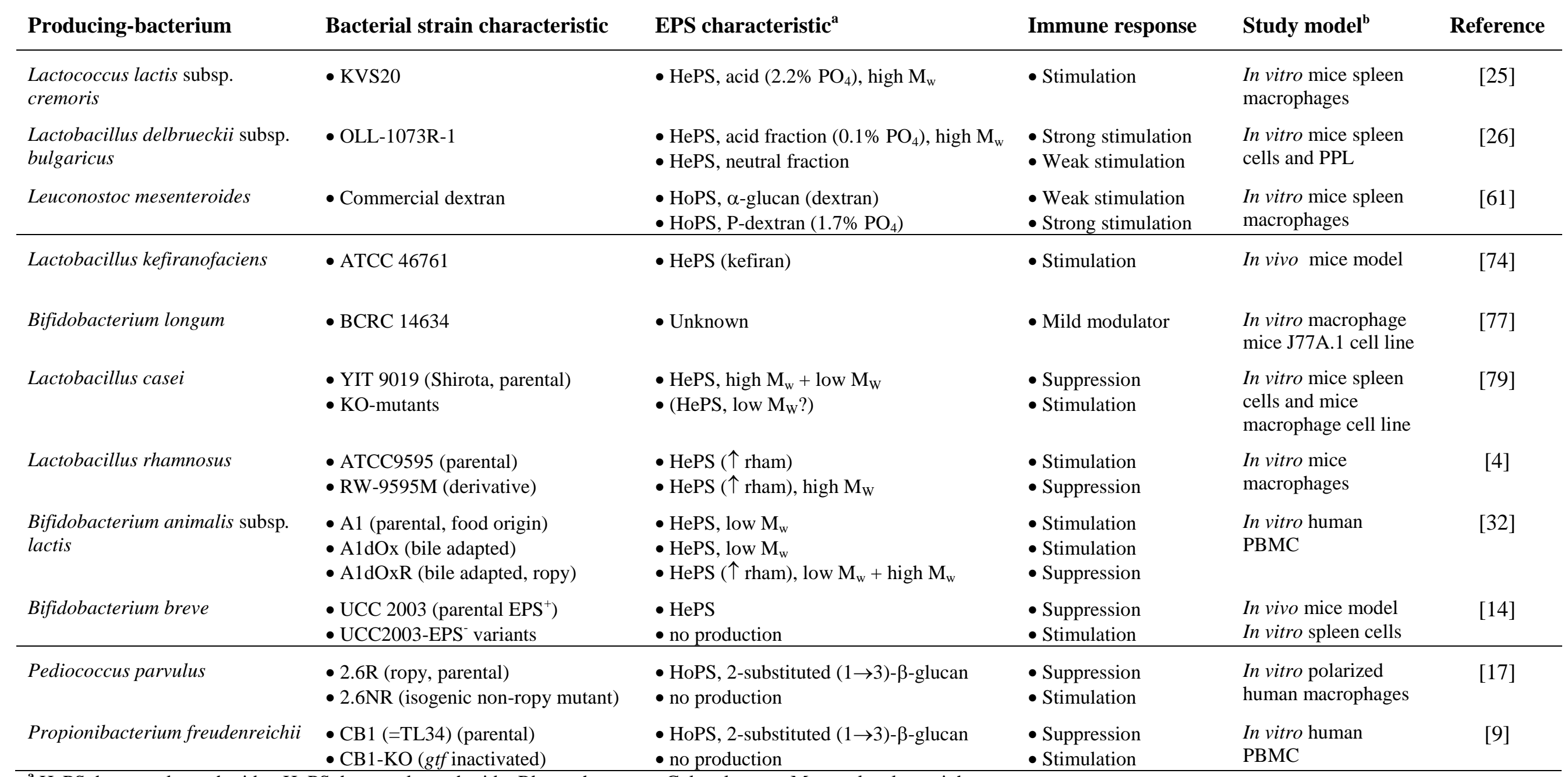

${ }^{a}$ HePS, heteropolysaccharide; HoPS, homopolysaccharide; Rham, rhamnose; Gal, galactose; $\mathrm{M}_{\mathrm{w}}$, molecular weight;

${ }^{\text {b }}$ PPL, Payer's Patches Lymphocytes; PBMC, peripheral blood mononuclear cells 


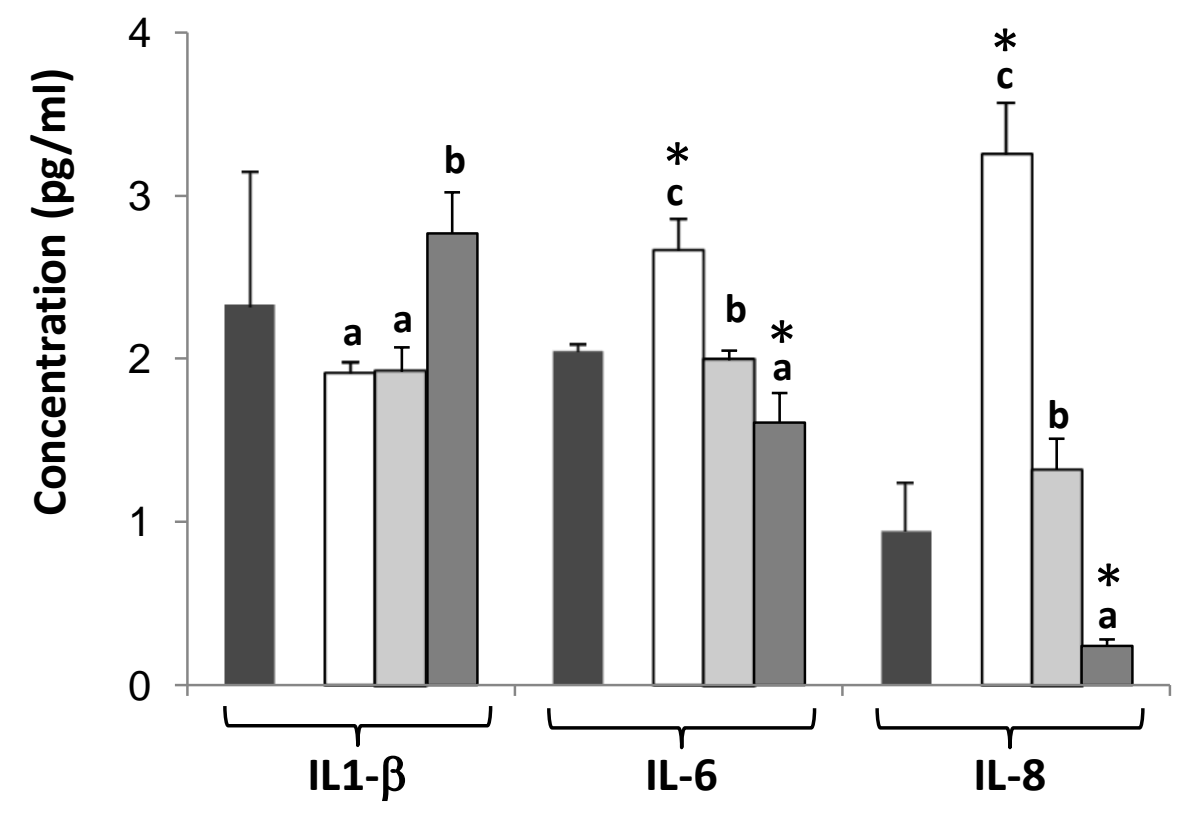

Figure 1 


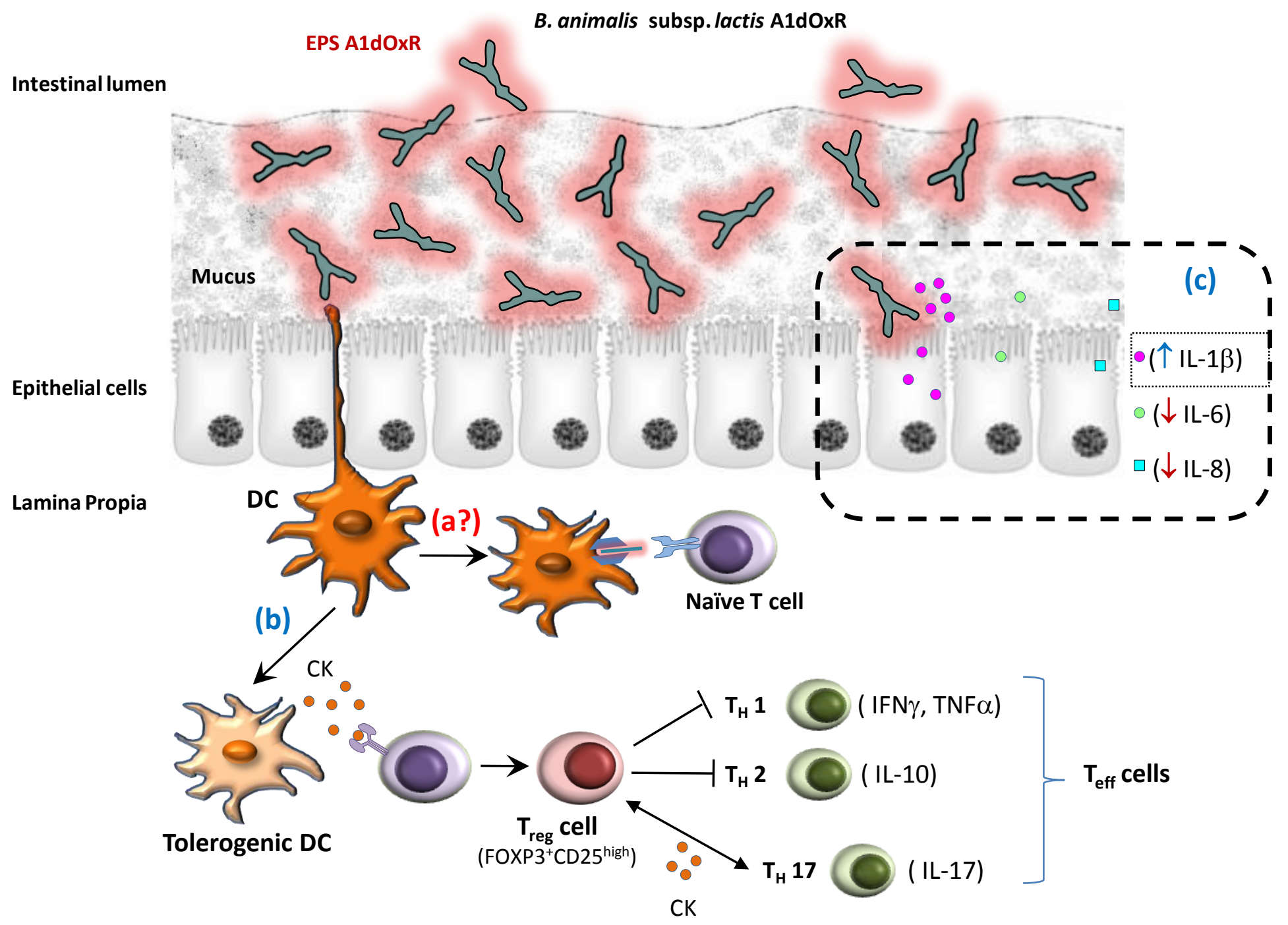

Figure 2 